\title{
Erratum to: Variations in Performance of Mental Health Providers in the English NHS: An Analysis of the Relationship Between Readmission Rates and Length-of-Stay
}

\author{
Valerie Moran ${ }^{2} \cdot$ Rowena Jacobs ${ }^{1} \cdot$ Anne Mason ${ }^{1}$
}

Published online: 13 February 2016

(c) Springer Science+Business Media New York 2016

\section{Erratum to: Adm Policy Ment Health DOI 10.1007/s10488-015-0711-4}

Unfortunately, during the correction process, the graphics for Figures 1, 2, 3, 4 were incorrectly positioned.

In the original online version, the graphic for Fig. 3 corresponded to the caption for Fig. 1 and this should have been the first graphic displayed. Similarly, the graphic for Fig. 4 corresponded to the caption for Fig. 2 and this should have been the second graphic displayed.

Hence, the figures and captions are corrected in this erratum.

The online version of the article has also been corrected.

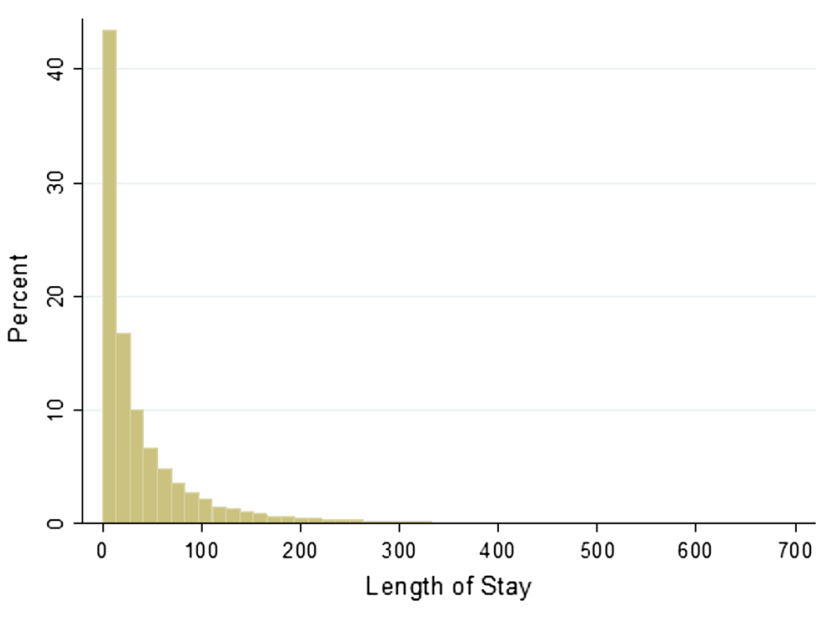

Figure 1 Length of Stay (LOS) by patient admission

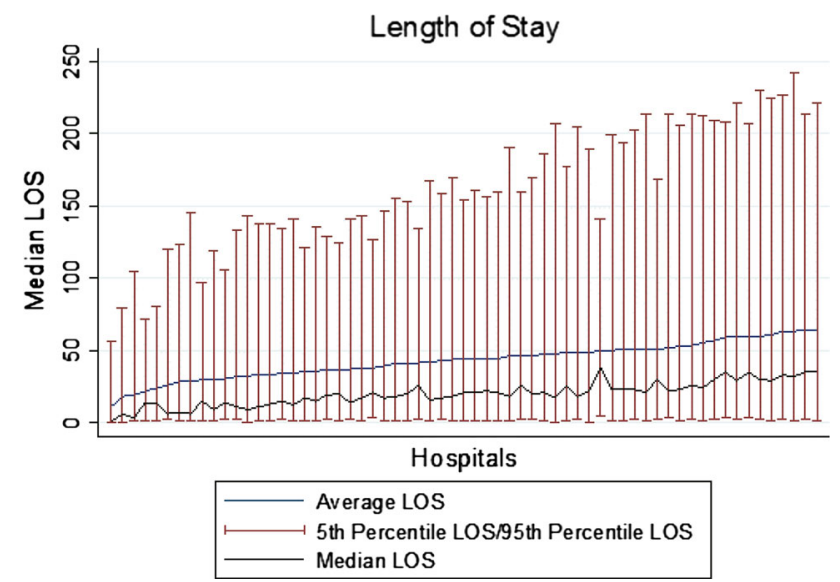

Figure 2 Variation in Length of Stay (LOS) between providers
The online version of the original article can be found under doi:10.1007/s10488-015-0711-4.

Valerie Moran

Valerie.Moran@1shtm.ac.uk

1 Centre for Health Economics and Department of Economics and Related Studies, University of York, Alcuin A Block, Heslington, York YO10 5DD, UK

2 Department of Health Services Research and Policy, Faculty of Public Health and Policy, London School of Hygiene and Tropical Medicine, 15-17 Tavistock Place,

London WC1H 9SH, UK 
Hospital 1
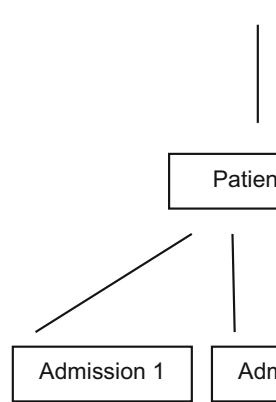

Patient 1

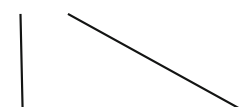

Hospital 2

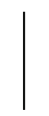

Patient 2

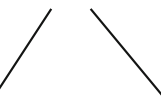

Admission 4
Level 3

Level 2

Level 1

Figure 3 Three-level model
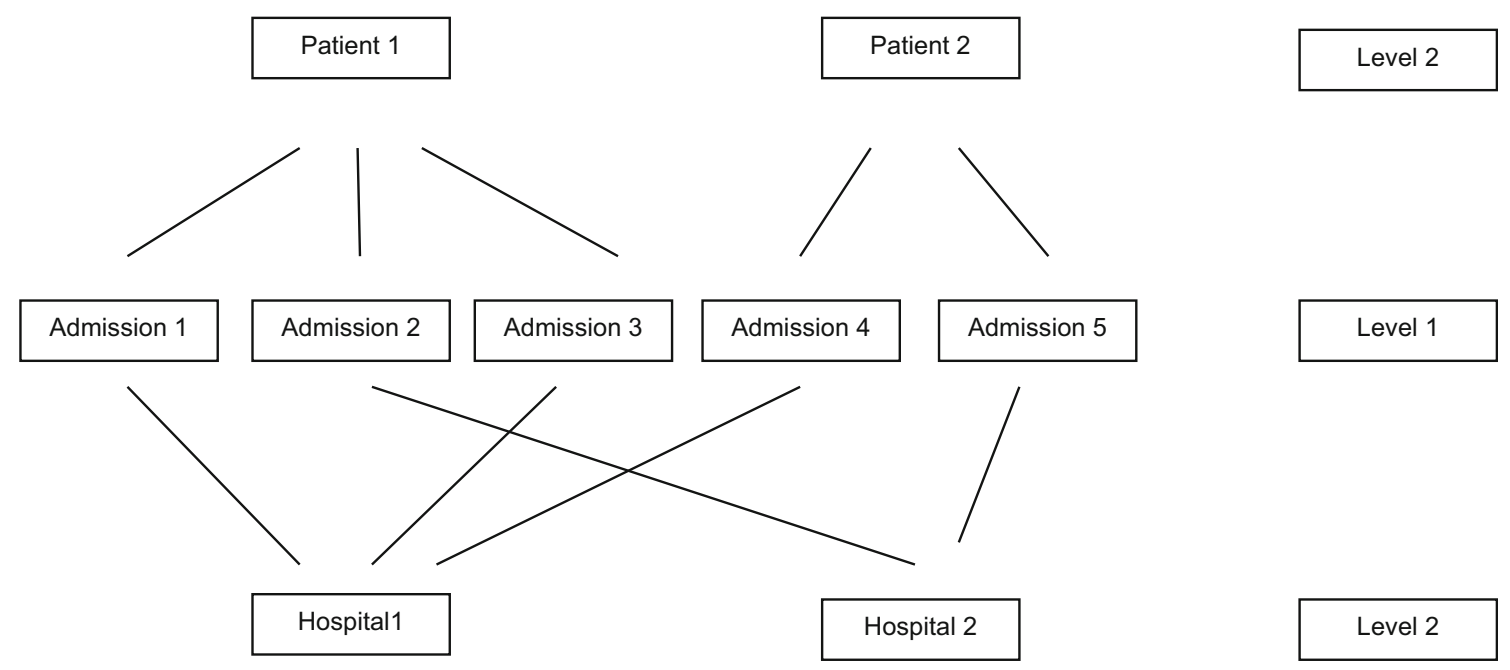

Figure 4 Cross-classified model 